\title{
REQUERIMENTO HÍDRICO E COEFICIENTE DE CULTURA DO MILHO E FEIJÃO-CAUPI EM SISTEMAS EXCLUSIVO E CONSORCIADO ${ }^{1}$
}

\author{
LUCIANA SANDRA BASTOS DE SOUZA ${ }^{2 *}$, MAGNA SOELMA BESERRA DE MOURA ${ }^{3}$, \\ GILBERTO CHOHAKU SEDIYAMA ${ }^{4}$, THIERES GEORGE FREIRE DA SILVA ${ }^{2}$
}

\begin{abstract}
RESUMO - Objetivou-se determinar a necessidade de água e o coeficiente de cultura para as diferentes fases fenológicas do milho (Zea mays L) e do feijão-caupi (Vigna unguiculata (L) Walp) em sistemas de plantio exclusivo e consorciado sob as condições climáticas do Semiárido brasileiro. O experimento foi conduzido no município de Petrolina, PE. Foram monitorados o rendimento de matéria seca total da parte aérea e a radiação fotossinteticamente ativa interceptada para ambas as culturas. Além disso, obteve-se a evapotranspiração da cultura (ETc) por meio do método do balanço de água no solo. Com estes dados e a evapotranspiração de referência foi obtido o coeficiente de cultura $(\mathrm{Kc})$, os quais foram utilizados, posteriormente, para ajustar modelos em função dos graus dias acumulados. Com os resultados, constatou-se que o requerimento hídrico do milho e feijão-caupi no sistema de plantio consorciado foi maior que no sistema exclusivo. Os valores de Kc no consórcio foram de $0,90,1,30,1,20$ e 0,72 para o milho, e 0,$86 ; 1,30,1,21$ e 0,91 para o feijão-caupi, respectivamente, para as fases vegetativa, floração, enchimento de grãos e maturação. No sistema exclusivo esses valores foram de, $0,86,1,23,0,97$ e 0,52 para o milho e de 0,$68 ; 1,02,1,06$ e 0,63 para o feijão-caupi, nesta ordem. As variações dos valores de Kc para ambos os sistemas e culturas estiveram associadas ao incremento de biomassa e a interceptação da radiação. O modelo Gaussiano ajustado descreveu adequadamente a relação entre os valores de Kc e dos graus dias acumulados.
\end{abstract}

Palavras-chave: Coeficiente de cultura. Demanda de água. Balanço de água no solo. Irrigação.

\section{WATER REQUIREMENT AND CROP COEFFICIENT OF MAIZE AND COWPEA IN SOLE AND INTERCROPPING SYSTEMS}

\begin{abstract}
In order to determine the water requirement and crop coefficient for the different phenological stages on corn plants (Zea mays L.) and cowpea plants (Vigna unguiculata (L.) Walp) in intercropping and sole cropping systems under the climatic conditions of the Brazilian semiarid. The experiment was conducted in the city of Petrolina, PE. Shoots total dry mass and photosynthetically active radiation intercepted for both crops were monitored. Furthermore, it was obtained the evapotranspiration (ETc) by the soil water balance method. With these data and reference evapotranspiration it was obtained crop coefficient $(\mathrm{Kc})$, which were subsequently used to adjust models as a function of accumulated degree days. With the results, it was found the water requirements from maize and cowpea intercropped system were greater than the sole system. Kc in the intercropped system was $0.90,1.30,1.20$ and 0.72 for maize and $0.86,1.30,1.21$ and 0.91 for cowpea, respectively, for the vegetative, flowering, grain filling and ripening stages. In the sole system, these values were, $0.86,1.23$, 0.97 and 0.52 for maize and $0.68,1.02,1.06$ and 0.63 for cowpea in those phases mentioned. The variations of the Kc values for both systems and cultures have been associated to the increase of biomass and light interception. The Gaussian model adjusted properly described the relationship between Kc and accumulated degree days.
\end{abstract}

Keywords: Crop coefficient. Water demand. Soil water balance. Irrigation. Intercropping.

\footnotetext{
*Autor para correspondência

${ }^{1}$ Recebido para publicação em 04/03/2014; aceito em 22/05/2015.

Resultado de projeto de pesquisa financiado pela MDA/EMBRAPA

${ }^{2}$ Unidade Acadêmica de Serra Talhada - UAST/UFRPE, Caixa Postal 063, CEP 56900-000, Serra Talhada, PE; sanddrabastos@yahoo.com.br, thieres_freire@yahoo.com.br.

${ }^{3}$ Embrapa Semiárido, BR 428, km 152, Caixa Postal 23, CEP 56302-970, Petrolina, PE; magna.moura@embrapa.br.

${ }^{4}$ Universidade Federal de Viçosa - UFV/DEA, CEP 36570-000, Viçosa, MG; g.sediyama@ufv.br.
} 


\section{INTRODUÇ̃̃O}

O milho (Zea mays L.) é uma cultura de grande importância agrícola, apresentando boa adaptação às condições edafoclimáticas brasileiras, além de ser uma ótima fonte proteica (CARVALHO et al., 2006; EVANGELISTA et al., 2005). Por sua vez, o feijãocaupi (Vigna unguiculata L.) é excelente fonte de proteínas, possui aminoácidos essenciais, teor de fibras e baixa quantidade de gorduras (CARDOSO et al., 1994; ANDRADE JÚNIOR et al., 2008).

Tais culturas são tradicionalmente exploradas na região Nordeste, usando-se, normalmente sistemas de plantio consorciados sob condições de sequeiro, resultando, em geral, em baixa produtividade, que atingem uma média de 812 e $317 \mathrm{~kg} \mathrm{ha}^{-1}$ para as culturas do milho e do feijão-caupi, respectivamente (FREIRE FILHO; RIBEIRO, 2005), sobretudo devido a grande irregularidade das chuvas e ao manejo inadequado, onde normalmente adotam-se níveis tecnológicos baixos nos sistemas de cultivo (OLIVEIRA et al., 2010; FERREIRA et al., 2007).

Todavia, deve-se salientar que a utilização de plantios consorciados pode melhorar a eficiência do uso da água; incrementar a viabilidade econômica e, ainda, possibilitar a produção diversificada em uma mesma área, contribuindo com o aumento da regularidade de suprimentos ao longo do tempo (ANDRADE JÚNIOR et al., 2008; SOUZA et al., 2011). Além disso, o consórcio permite melhorar o aproveitamento de mão de obra, reduzir os riscos de perda de produção devido às irregularidades climáticas, protege o solo e, finalmente, melhora a distribuição de renda entre os produtores (ANDRADE et al., 2001).

No entanto, para expressão do potencial produtivo do sistema de plantio e obtenção de melhores rendimentos a determinação das necessidades hídricas do sistema é de extrema importância uma vez que pode contribuir para um melhor crescimento, eficiência do uso da água, manejo de irrigação e mesmo na realização de zoneamentos (ANDRADE JUNIOR et al., 2008; SOUZA et al., 2011). Neste sentido, diferentes metodologias têm sido adotadas em campo para obtenção do requerimento hídrico das culturas por meio da evapotranspiração da cultura, estes incluem métodos micrometeorológicos e do balanço de água no solo por meio do uso de sondas ou lisímetros e podem resultar em indicadores a serem utilizados no manejo racional da irrigação (POSSE et al., 2008; SILVA et al., 2012). Dentre os indicadores utilizados está o coeficiente de cultura $(\mathrm{Kc})$, que compreende a relação entre a evapotranspiração da cultura e a evapotranspiração de referência, e que é dependente da espécie, altura, área foliar, altura e manejo da cultura (ALLEN et al., 1998). Vários trabalhos têm reportado valores de Kc determinados em campo para as culturas do milho e do feijão-caupi em sistemas de plantio exclusivos (PAYERO et al., 2008; DETAR, 2009; BASTOS et al., 2008).

Valores de Kc também têm sido recomendados pela Food and Agriculture Organization (FAO), entretanto, estes compreendem dados médios obtidos para diferentes regiões do mundo que levam em consideração a duração dos estádios fenológicos da cultura que pode variar em função do clima local (BASTOS et al., 2008; RIBEIRO et al., 2009). Para minimizar tal problema, tem-se procurado relacionar os graus-dia acumulados com os valores de $\mathrm{Kc}$ em substituição ao tempo decorrido, objetivando-se uma maior precisão na duração das fases fenológicas (LIMA; SILVA, 2008; RIBEIRO et al., 2009; TEIXEIRA et al., 2012).

No caso dos sistemas consorciados, a questão é complexa uma vez que estudos para determinar o requerimento de água das culturas são escassos (GAO et al., 2009). Assim, objetivou-se determinar a necessidade de água e o coeficiente de cultura do milho e feijão-caupi em sistemas de plantio exclusivo e consorciado sob as condições de Semiárido brasileiro, bem como ajustar modelos para a estimativa dos valores de $\mathrm{Kc}$ em função dos graus dias acumulados.

\section{MATERIAL E MÉTODOS}

O experimento foi executado no Campo Experimental de Bebedouro da Embrapa Semiárido, em Petrolina-PE (0909' S, 40²2' W, 365,5m), cujo clima é classificado, segundo Köppen, como BSwh', ou seja, Semiárido com estação chuvosa compreendida entre os meses de janeiro e abril, sendo a média anual acumulada de $550 \mathrm{~mm}$ e temperaturas médias elevadas da ordem de $26,2^{\circ} \mathrm{C}$. O solo da área experimental é classificado como Argissolo, com lençol freático a $1,80 \mathrm{~m}$ de profundidade. As características físico-químicas foram determinadas a cada $0,1 \mathrm{~m}$, até a profundidade de $1 \mathrm{~m}$, no Laboratório de Solos, Água e Planta da Embrapa Semiárido.

A área experimental foi semeada com as cultivares Caatingueiro para o milho (Zea mays L.) e Pujante para o feijão-caupi (Vigna ungüiculada L.), que são adaptadas às condições de clima Semiárido. A semeadura foi realizada no dia 20 de dezembro de 2007 e, após esta data, foram realizados os tratos culturais como capina e controle de pragas e doenças de acordo com recomendações de técnicos da Embrapa para as culturas.

A necessidade hídrica e o coeficiente de cultura para o milho e feijão-caupi, nos dois sistemas de plantio, foram estabelecidos para condições potenciais de cultivo, ou seja, para àquelas condições em que as culturas apresentassem maior desempenho produtivo. Para isso, além de serem submetidas às três configurações quanto aos sistemas de plantio (sistema exclusivo do milho, sistema exclusivo do feijão-caupi e sistema consorciado milho e feijãocaupi), as mesmas foram impostas a cinco lâminas de 
irrigação diferenciadas com base nos valores da evapotranspiração de referência (ETo), como segue: $\mathrm{L} 125=125 \% \times \mathrm{ETo}, \mathrm{L} 100=100 \% \times \mathrm{ETo}, \mathrm{L} 75=$ $75 \% \times$ ETo, L50 $=50 \% \times$ ETo e L0 $=0 \%$ x ETo, aplicadas após os primeiros 40 dias de ciclo. No período antecedente, a lâmina aplicada correspondeu a $100 \%$.ETo.

Adotou-se o delineamento experimental inteiramente casualizado, em esquema de três repetições, com espaçamento de $0,5 \times 0,5 \mathrm{~m}$, com duas plantas por cova, para o caso do feijão-caupi no sistema exclusivo (80.000 plantas ha ${ }^{-1}$ ); e $1,0 \times 0,5 \mathrm{~m}$ entre plantas de feijão-caupi, com duas plantas por cova (40.000 plantas ha $^{-1}$ ) e $1,0 \times 0,2 \mathrm{~m}$ entre plantas de milho em ambos os sistemas de plantio (50.000 plantas $\left.\mathrm{ha}^{-1}\right)$. Nos sistemas de cultivo exclusivos, a parcela experimental foi composta por quatro fileiras de $16 \mathrm{~m}$ de comprimento. Por outro lado, no sistema consorciado, a parcela foi formada pela associação de uma fileira de feijão-caupi e uma fileira de milho, ambas com $16 \mathrm{~m}$ de comprimento, o que resultou em seis fileiras para cada parcela experimental.

Utilizou-se o sistema de irrigação por gotejamento com linhas laterais de $17 \mathrm{~mm}$ de diâmetro externo, gotejadores na linha tipo autocompensantes e autolimpantes, espaçados de $0,5 \mathrm{~m}$, com uma vazão média de $1,8 \mathrm{~L} \mathrm{~h}^{-1}$ e um coeficiente de uniformidade igual a 95,03\%. A lâmina de irrigação foi obtida com base na evapotranspiração de referência (ETo), com turno de rega a cada dois dias.
Para determinação dos valores da fração da radiação fotossinteticamente ativa interceptada (fRFA), foram instalados quatro sensores quânticos lineares (LI-191SA Line Quantum Sensor Li-cor, Nebraska, USA), sendo um localizado acima das culturas $\left(\mathrm{RFA}_{\mathrm{T}}\right)$, e os outros três dispostos de maneira perpendicular a fileiras, abaixo do dossel da vegetação $\left(\mathrm{RFA}_{\mathrm{B}}\right)$.

Para obtenção da biomassa seca acumulada, foram amostradas, ao acaso três plantas de milho aos $8,19,26,33,40,54,63,68,78,88,97$ e 109 dias após a semeadura (DAS) e de feijão-caupi aos 7,18 , $25,32,39,53,62,67$ e 76 (DAS), em cada um dos sistemas de plantio. As plantas foram colocadas em sacos de papel e levadas à estufa com ventilação forçada à temperatura de $70^{\circ} \mathrm{C}$, onde permaneceram por um período de $72 \mathrm{~h}$. Após este período, as amostras foram pesadas, utilizando-se uma balança com precisão de 0,001 g (Modelo MARK 210A, Bel Engineering, Monza-MI, Itália), até se obter peso constante e, consequentemente, ter-se a matéria seca das plantas. A fenologia das culturas foi observada por meio de visitas diárias a área experimental, quando foram identificadas as datas de ocorrência dos eventos fenológicos e delimitadas a duração dos subperíodos de crescimento e desenvolvimento, adotando-se o método proposto por Fernandéz et al. (1982) para a cultura do feijão-caupi e por Fancelli e Dourado Neto (2000) para o milho. Sendo delimitados os seguintes subperíodos e durações para ambas as culturas:

Tabela 1. Delimitação das fases fenológicas para o milho e feijão-caupi sob as condições climáticas do Semiárido brasileiro.

\begin{tabular}{lccc}
\hline Estádio de desenvolvimento & Fase & Milho (dias) & Feijão-caupi (dias) \\
Vegetativo & I & 40 & 30 \\
Floração & II & 13 & 21 \\
Enchimento de grãos & III & 20 & 12 \\
Maturação & IV & 36 & 16 \\
Total & - & 109 & 79 \\
\hline
\end{tabular}

A umidade do solo foi determinada em tubos de acesso instalados em cada sistema de plantio até a profundidade de $1 \mathrm{~m}$, sendo as leituras efetuadas a cada $0,1 \mathrm{~m}$. As medidas foram realizadas diariamente, durante todo ciclo, por meio de uma sonda FDR modelo Diviner@2000 (Sentek Pty Ltd., Austrália).

Para o cálculo do balanço hídrico considerouse o somatório do armazenamento de água no solo nas camadas de 0 a $0,5 \mathrm{~m}$, uma vez que nessa, estão concentrados cerca de $80 \%$ do sistema radicular do milho e do feijão-caupi (FERREIRA et al., 2008; ALBUQUERQUE, 2010).

O monitoramento das condições meteorológicas durante o período de execução do experimento foi realizado por meio de uma estação agrometeorológica automática localizada a $400 \mathrm{~m}$ da área experimental. A estação é composta de um datalogger modelo CR10X (Campbell Scientific INC.), sensores de temperatura e umidade relativa do ar, velocidade e direção do vento, radiação solar incidente, saldo de radiação e fluxo de calor no solo e precipitação. Os elementos meteorológicos foram medidos a cada 60 segundos, e as médias armazenadas a cada 30 minutos. Estes dados meteorológicos foram utilizados no cálculo da evapotranspiração de referência diária (ETo), de acordo com a metodologia de PenmanMonteith parametrizada no boletim 56 da FAO (ALLEN et al., 1998):

$$
\text { ETo }=\frac{0,408 \Delta\left(\mathrm{R}_{\mathrm{n}}-\mathrm{G}\right)+\gamma \frac{900}{\mathrm{t}_{\mathrm{m}}+273} \mathrm{u}_{2}\left(\mathrm{e}_{\mathrm{s}}-\mathrm{e}_{\mathrm{a}}\right)}{\Delta+\gamma\left(1+0,34 \mathrm{u}_{2}\right)}
$$

em que, Rn - saldo de radiação sobre a superfície da cultura de referência $\left(\mathrm{MJ} \mathrm{m}^{-2} \mathrm{~d}^{-1}\right) ; \mathrm{G}$ - fluxo de calor no solo $\left(\mathrm{MJ} \mathrm{m}^{-2} \mathrm{~d}^{-1}\right) ; \gamma$ - constante psicrométrica $\left(\mathrm{kPa}{ }^{\circ} \mathrm{C}^{-1}\right) ; \mathrm{t}_{\mathrm{m}}$ - temperatura do ar $\left({ }^{\circ} \mathrm{C}\right) ; \mathrm{u}_{2}$ - velocidade do vento $\left(\mathrm{m} \mathrm{s}^{-1}\right) ;\left(\mathrm{e}_{\mathrm{s}}-\mathrm{e}_{\mathrm{a}}\right)$ - déficit de pressão vapor d'água $(\mathrm{kPa}) ; \Delta$ - declividade da curva de pressão de 
saturação de vapor d'água $\left(\mathrm{kPa}{ }^{\circ} \mathrm{C}^{-1}\right)$.

A evapotranspiração da cultura (ETc) foi obtida pelo método simplificado do balanço de água no solo, considerando o escoamento superficial como nulo devido ao relevo plano do local, o orvalho foi desprezível, logo que o mesmo foi conduzido em ambiente semiárido e os movimentos ascendentes e descendentes no solo não foram admitidos, uma vez que não houve variação nos valores diários de umidade do solo abaixo da camada do solo de $0,5 \mathrm{~m}$. (FERREIRA et al., 2008; OLIVEIRA, 2010): Assim, a equação do balanço de água no solo assumida foi

$$
\mathrm{ETc}=\mathrm{P}+\mathrm{I}-\Delta \mathrm{ARM}
$$

em que, ETc - evapotranspiração da cultura (mm); P - precipitação (mm); I - irrigação (mm); $\triangle \mathrm{ARM} \mathrm{-}$ variação do conteúdo de água no solo até a profundidade de $0,5 \mathrm{~m}(\mathrm{~mm})$.

$\mathrm{O}$ requerimento hídrico para ambas as culturas e sistemas de plantio foi determinado integrandose os valores de ETc para todo o periodo monitorado, no caso de dias sem dados, estes valores foram extrapolados para todo o ciclo, utilizando-se o coeficiente de cultura médio para cada fase e os valores da evapotranspiração de referência diária.

Considerando a evapotranspiração da cultura determinada pelo método simplificado do balanço hídrico no solo, o coeficiente de cultura $(\mathrm{Kc})$ foi obtido para o milho e o feijão-caupi, nos sistemas de plantio exclusivo e consorciado. Para efeito do cálculo dos valores médios foram consideradas as fases fenológicas descritas na tabela 1. Para isso, foi considerada a relação entre os valores de ETc e ETo, conforme Allen et al. (1998):

$$
\mathrm{Kc}=\frac{\mathrm{ETc}}{\mathrm{ETo}}
$$

em que, Kc - coeficiente de cultura (adimensional).

Com os valores determinados de $\mathrm{Kc}$, foi possível ajustar o modelo de Gaussiano com três parâmetros em função dos graus-dia acumulados (GDA), obtida por meio da realização de uma regressão não linear utilizando o software SigmaPlot ${ }^{\circledR} 11$ (Systat Software Inc.). O GDA foi determinado considerando a ocorrência dos eventos fenológicos e os dados de temperatura do ar obtidos na estação agrometeorológica automática. Este procedimento foi realizado para cada uma das culturas, adotando-se a temperatura base de $10^{\circ} \mathrm{C}$, tanto para o milho como para o feijão-caupi (LOZADA; ANGELOCCI, 1999).

\section{RESULTADOS E DISCUSSÃO}

Os dados dos elementos meteorológicos radiação solar global $(\mathrm{Rg})$, temperatura do ar $\left(\mathrm{t}_{\mathrm{ar}}\right)$, umidade relativa do ar (UR), velocidade do vento (Vv), precipitação e evapotranspiração de referência (ETo) são apresentados na Figura 1. Na FASE I tanto para o milho (40 DAS) quanto para o feijão-caupi (30 DAS) foi observada a ocorrência de temperaturas elevadas (Figura 1a), com tendência à redução ao final do período experimental. No caso da umidade relativa do ar (UR) no início do ciclo foram registrados valores baixos (Figura 1a), entretanto, a partir de fevereiro, com o início da ocorrência de precipitação, verificaram-se aumentos da nebulosidade na região. Devido a isto, observou-se uma tendência de redução da radiação solar (Figura 1b), contribuindo para a diminuição dos valores da evapotranspiração de referencia (ETo), conforme pode ser verificado na Figura $1 \mathrm{c}$. Houve maior variação na velocidade do vento no início do cultivo, ocorrendo redução até no final dos ciclos (Figura 1b). Embora alguns dias do ciclo das culturas tenham ocorrido no período chuvoso, observou-se que os eventos de precipitação não ocorreram durante a aplicação dos tratamentos (Figura 1c); sendo que a lâmina total precipitada durante o desenvolvimento das culturas foi em torno de $118,6 \mathrm{~mm}$.

$\mathrm{O}$ requerimento hídrico e o coeficiente de cultura para o sistema de plantio do milho exclusivo, sistema de plantio do feijão exclusivo e para o consórcio milho e feijão-caupi foram definidos a partir dos dados dos tratamentos de $100 \%$ x ETo, logo que apresentaram bons desempenhos produtivos. No sistema de plantio exclusivo, as culturas do milho e do feijão-caupi receberam lâminas de água $(\mathrm{P}+\mathrm{I})(471,2$ e 448,7 mm, respectivamente) inferiores as recebidas no sistema de plantio consorciado (nesta mesma ordem, 529,8 e 491,7 mm).

Observa-se que, em ambos os casos a FASE I foi caracterizada por um baixo acúmulo de fitomassa e interceptação da radiação $(\sim 30 \%, 15 \%$ e $30 \%$ para o milho, feijão-caupi e consorcio, nesta ordem) (Figuras 2 e 3 ). Posteriormente, na FASE II com o incremento da fitomassa seca total acumulada, sendo maior parte desta destinada às folhas houve uma tendência de acréscimo da radiação fotossinteticamente ativa interceptada, com um valor médio de $60 \%$ para o milho e o feijão-caupi. Comportamento também observado por Silva et al. (2012) em estudo realizado para a cana-de-açúcar. No caso do sistema consorciado, a presença de plantas com arquiteturas diferentes promoveu um incremento da fRFA, que atingiu valores médios na segunda fase iguais a $80 \%$. Na terceira fase, tanto o milho quanto o consórcio apresentaram maiores níveis de interceptação da radiação, em torno $70 \%$ e $95 \%$, respectivamente. Com posterior tendência à redução, em decorrência da abscisão das folhas, que promoveu uma redução da área foliar e consequentemente da fRFA. O feijão-caupi em sistema exclusivo na FASE III ainda continuou apresentando incrementos da fRFA devido a uma maior manutenção da fitomassa das folhas nesta cultura, que começou a apresentar uma perda destes órgãos apenas no final da FASE IV. 


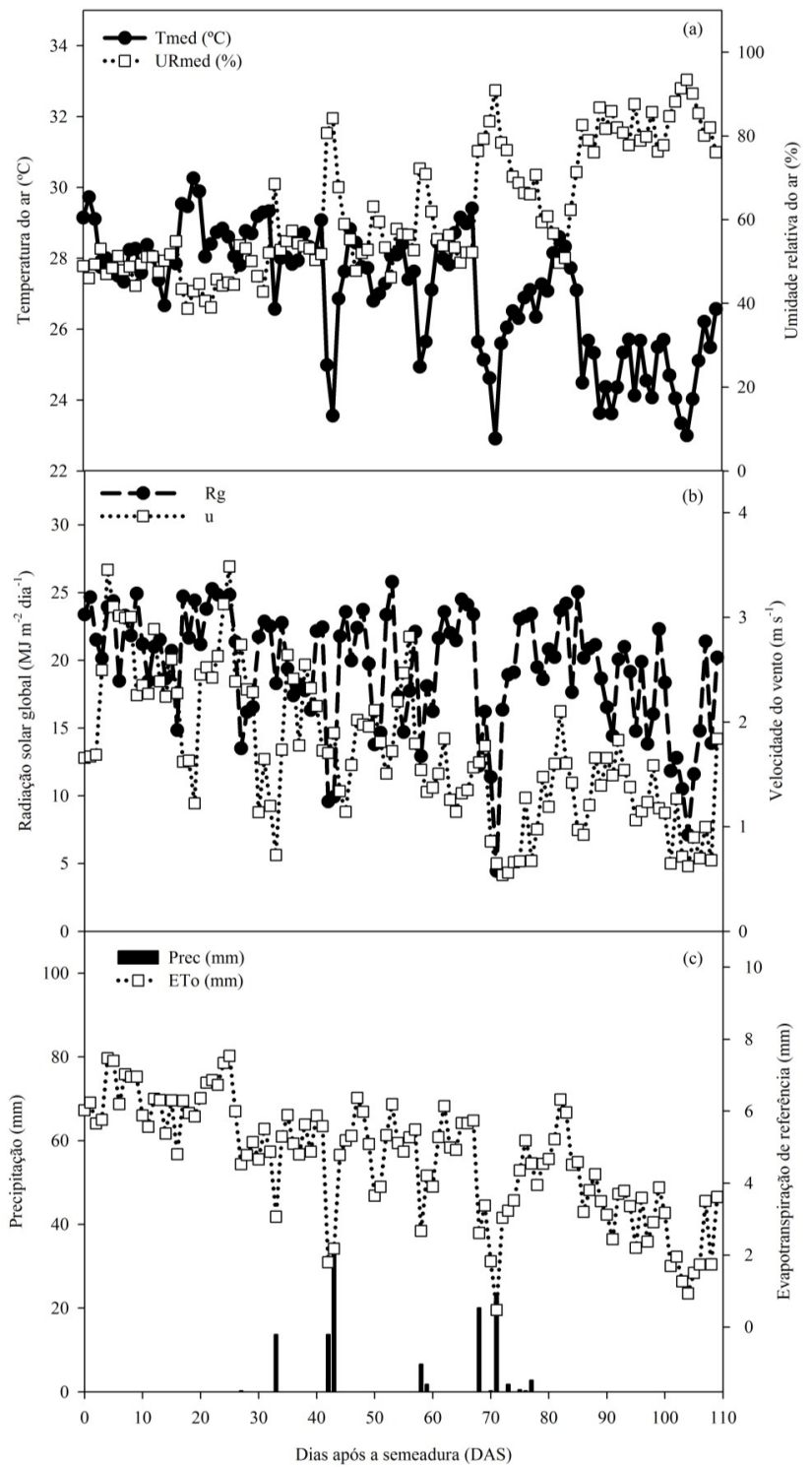

Figura 1. Dados meteorológicos médios diários ao longo do ciclo das culturas do milho (Zea mays) e do feijão-caupi (Vigna unguiculata) nos sistemas de plantio exclusivo e consorciado, sob as condições climáticas do município de Petrolina $-\mathrm{PE}$
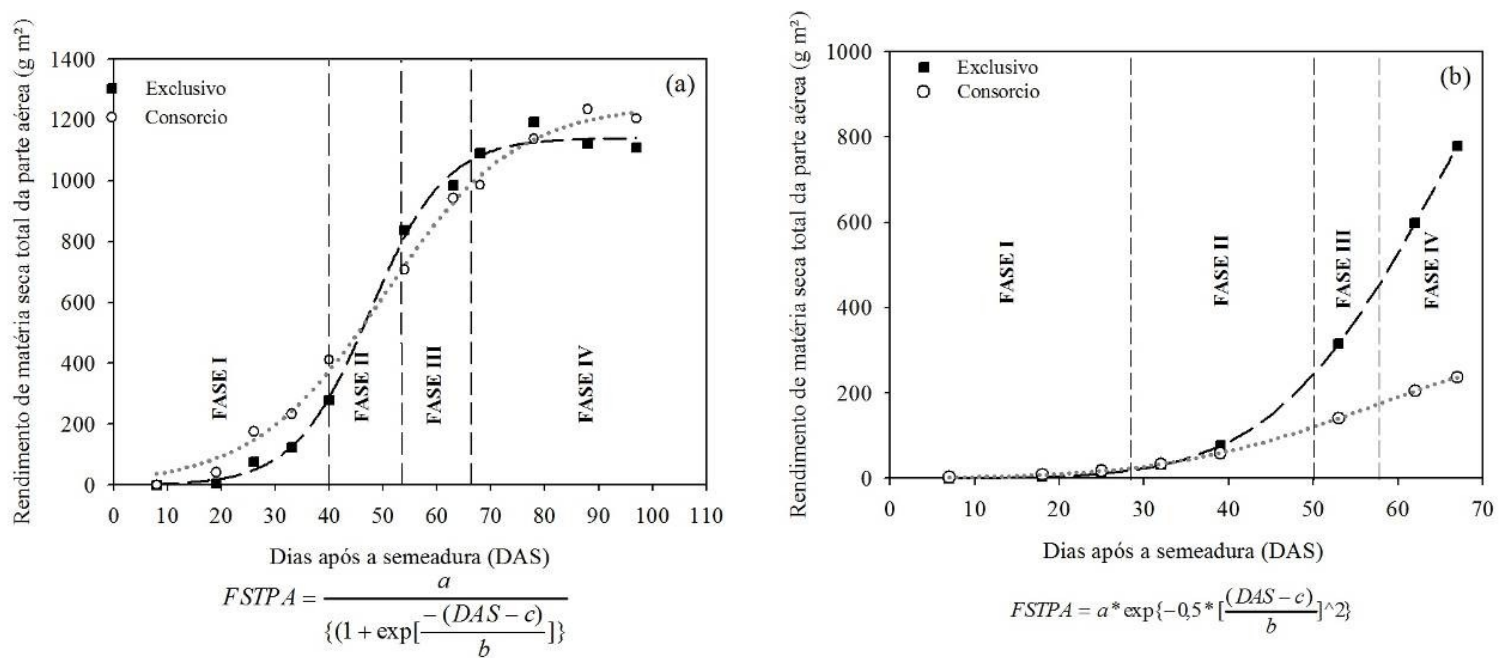

Figura 2. Rendimento de matéria seca total da parte aérea do milho (Zea mays) (a) e feijão-caupi (Vigna unguiculata) (b) em sistemas de plantio exclusivo e consorciado, submetidas a diferentes lâminas de irrigação sob as condições climáticas do município de Petrolina - PE

Revista Caatinga, Mossoró, v. 28, n. 4, p. 151 - 160, out. - dez., 2015 

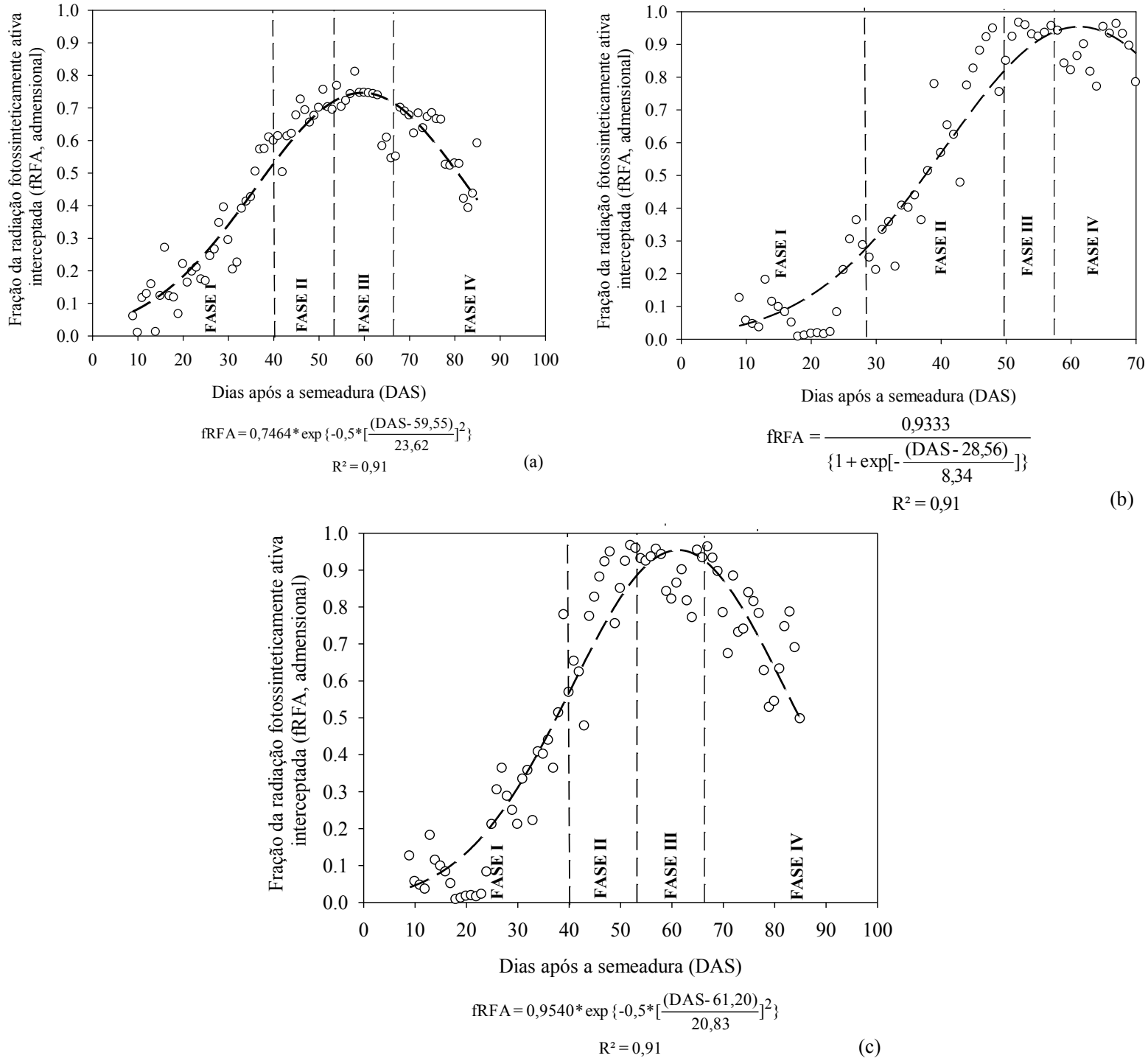

Figura 3. Fração da radiação fotossinteticamente ativa interceptada pelo sistema exclusivo do milho (Zea mays) (a), feijão-caupi (Vigna unguiculata) (b) e do sistema consorciado (d), sob as condições climáticas do município de Petrolina $\mathrm{PE}$

$\mathrm{O}$ requerimento hídrico da cultura do milho durante o ciclo no sistema exclusivo $(387,1 \mathrm{~mm})$ foi $12 \%$ inferior a necessidade de água do sistema consorciado (439,4 mm) (Figura 4a). Tais valores são inferiores aos obtidos por Suyker e Verma (2009), que determinaram a evapotranspiração do milho em sistema exclusivo $(683 \mathrm{~mm})$ na região de Mead em Nebraska. Tendência semelhante foi verificada para o feijão-caupi, quando se observou que o requerimento hídrico do sistema exclusivo $(322,6 \mathrm{~mm})$ foi $21 \%$ inferior ao do sistema consorciado $(408,4 \mathrm{~mm})$ (Figura 4b). Vários são os estudos que citam que a demanda de água em um sistema consorciado tende a ser superior em relação ao sistema exclusivo (ANDRADE JÚNIOR et al., 2008; OLIVEIRA, 2010).

Para o milho, em ambos os sistemas de plantio, a ETc foi inferior a evapotranspiração de referência (ETo) acumulada $(450,6 \mathrm{~mm})$. Quando se analisaram a ETc e a ETo ao longo do tempo, percebeu- se, que apenas durante a FASE I e IV, a ETc foi menor do que a ETo (Figura 4a). Entre a FASE II e III, essa tendência se inverteu, coincidindo com as fases de florescimento e enchimento de grãos e com a maior interceptação de radiação, quando a ETc atingiu valores médios diários iguais a $5,3 \mathrm{~mm} \mathrm{dia}^{-1}$ e 6,3 $\mathrm{mm} \mathrm{dia}{ }^{-1}$ nos sistemas exclusivo e consorciado, respectivamente, caracterizando-se o período de maior demanda hídrica da cultura do milho, em ambos os sistemas de plantio.

No início do ciclo do feijão-caupi, a evapotranspiração de cultura foi relativamente baixa, igual a 4,23 $\mathrm{mm} \mathrm{dia}^{-1}$ para o feijão-caupi em sistema exclusivo e $5,35 \mathrm{~mm} \mathrm{dia}^{-1}$ quando o consorciado. Com o crescimento da cultura, o incremento da área foliar e o surgimento dos órgãos reprodutivos da cultura, houve um aumento da interceptação da radiação e da demanda hídrica, que alcançou valores máximos na fase de enchimento de grãos, com uma evapotranspiração média diária igual a $5,2 \mathrm{~mm} \mathrm{dia}^{-1} \mathrm{e}$ 
$6,4 \mathrm{~mm} \mathrm{dia}^{-1}$ para os respectivos sistemas de plantios, na ordem em que foram citados. Posteriormente, por ocasião da FASE IV foi observada a abscisão das folhas, com isso, houve uma diminuição da área foli- ar e o consumo de água da cultura foi reduzido para $2,5 \mathrm{~mm} \mathrm{dia}^{-1}$ e $3,6 \mathrm{~mm} \mathrm{dia}{ }^{-1}$ para os sistemas exclusivo e consorciado, respectivamente.
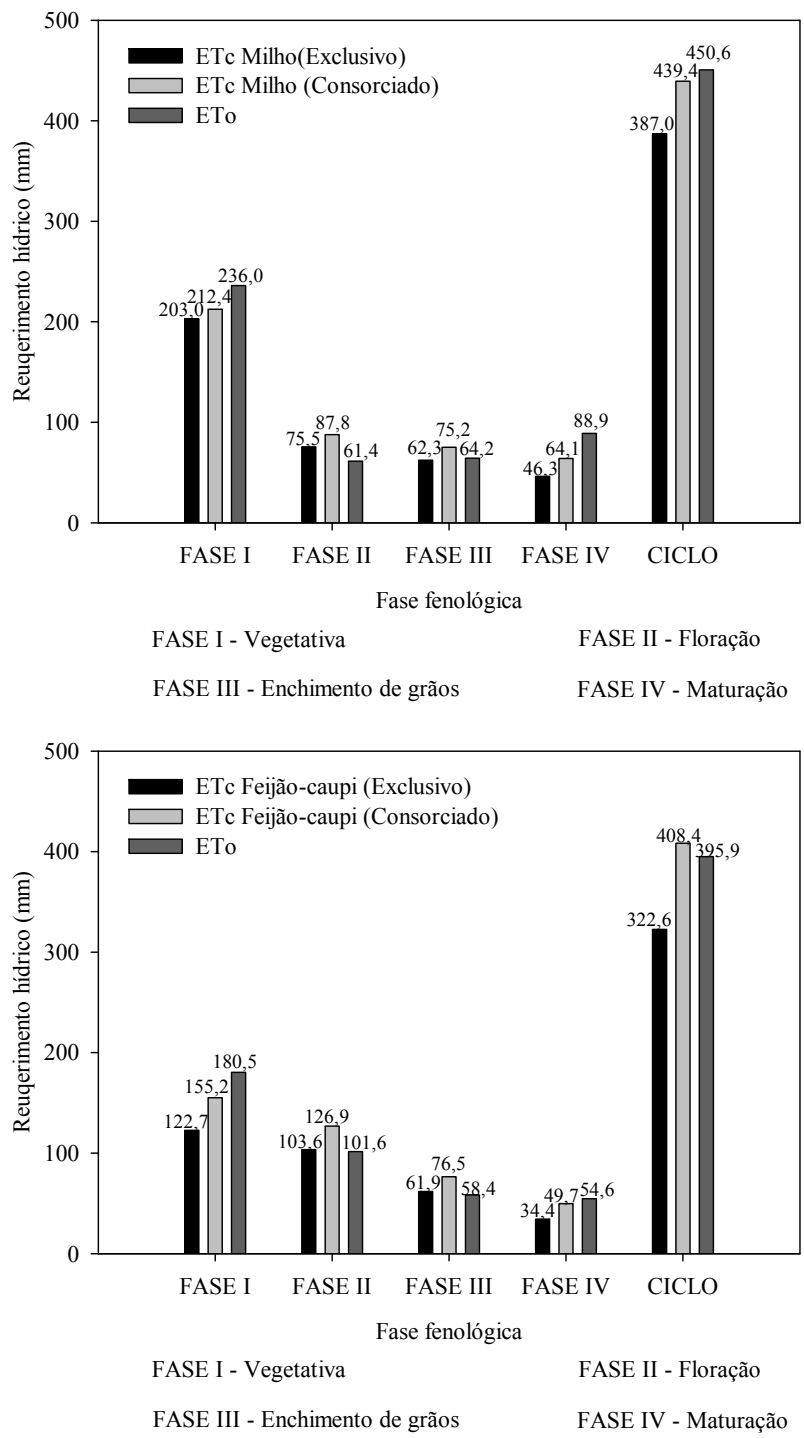

Figura 4. Requerimento de água do milho (Zea mays) e feijão-caupi (Vigna unguiculata), relativo à cada fase de desenvolvimento e para todo o ciclo, sob sistemas de plantio exclusivo e consorciado), sob as condições climáticas do município de Petrolina - PE

Os resultados encontrados para o feijão-caupi, no presente estudo, foram superiores aos observados por Bastos et al. (2008a) que, em trabalho realizado no Vale do Gurgéia - PI, encontraram a evapotranspiração acumulada para o sistema exclusivo de 288,5 $\mathrm{mm}$, sendo o estádio reprodutivo, o de maior consumo de água, com uma média de $5,4 \mathrm{~mm} \mathrm{dia}^{-1}$. Todavia, foram inferiores aos obtidos por Lima et al. (2006) que, realizando o balanço hídrico para a cultura do feijão-caupi nas condições climáticas de Areia-PB, obtiveram um valor de evapotranspiração acumulada durante todo o ciclo da ordem de 383 $\mathrm{mm}$.

Os valores de Kc para cada fase fenológica das culturas do milho e feijão-caupi nos sistemas PE e PC são apresentados na Tabela 2. Constatou-se que, para a cultura do milho em sistema consorciado, o Kc médio da Fase I foi de 0,90. Na Fase II, o aumento do crescimento (Figura 1) resultou em um incremento da evapotranspiração e consequentemente do Kc $(1,3)$, que permaneceram elevados na FASE III (Tabela 2), caracterizando-se por apresentar a maior demanda de água ao longo do ciclo. Esta tendência tem sido observada para o Kc do milho em diferentes regiões (ALLEN et al., 1998; BEZERRA; OLIVEIRA, 1999; CARVALHO et al., 2006; BASTOS et al., 2008b). Na Fase IV, modificações fisiológicas como amarelamento e senescência das folhas promoverão diminuição nos valores de Kc para 0,72. 
L. S. B. SOUZA et al.

Tabela 2. Valores médios dos coeficientes de cultura $(\mathrm{Kc})$ do milho irrigado em sistema de plantio exclusivo nas diferentes fases fenológicas, sob as condições de Semiárido brasileiro, Petrolina-PE, 2008

\begin{tabular}{lcccc}
\hline \multirow{2}{*}{\multicolumn{1}{c}{ Método }} & \multicolumn{3}{c}{} & Fase Fenológica \\
\cline { 2 - 5 } & I & II & III & IV \\
Vegetativo & Floração & Enchimento de grãos & Maturação \\
\hline Milho exclusivo & 0,86 & 1,23 & 0,97 & 0,52 \\
Feijão-caupi exclusivo & 0,68 & 1,02 & 1,06 & 0,63 \\
Milho consorciado & 0,90 & 1,30 & 1,20 & 0,72 \\
Feijão-caupi consorciado & 0,86 & 1,30 & 1,21 & 0,91 \\
\hline
\end{tabular}

$\mathrm{O}$ valor médio do $\mathrm{Kc}$ do milho no sistema exclusivo foi próximos aos do sistema consorciado apenas na FASE I, sendo observado nas demais FASES valores mais elevados para o sistema consorciado. Bastos et al. (2008b), em trabalho realizado para determinar o coeficiente de cultura para o milho exclusivo irrigado por aspersão, por meio da utilização de lisímetros, encontraram valores de Kc oscilando entre $0,5-0,7 ; 1,1-1,3 ; 1,3-1,4$ e 0,6 para as fases I, II, III e IV, respectivamente, sob as condições edafoclimáticas dos Tabuleiros Litorâneos do Piauí. Bezerra e Oliveira (1999) utilizaram o método do balanço de água e um sistema de irrigação por gotejamento para determinar o Kc do milho sob o sistema de plantio exclusivo, em Fortaleza - CE e encontraram valores de 0,$73 ; 1,11 ; 0,95$ e 0,64 para referidas fases.As variações observadas nos valores de Kc, indicam a necessidade de sua determinação local devido a sua dependência em relação ao clima, solo e cultivar (FERREIRA et al., 2007). Para o milho, em sistema consorciado, Ferreira et al. (2007) encontraram valores de 0,$90 ; 1,48$ e 1,06 para as fases de semeadurapendoamento, pendoamento-espigamento e espigamento-maturidade fisiológica, nessa ordem.

No caso do feijão-caupi, em sistema exclusivo, verificou-se que o Kc no estádio inicial foi de
0,68 . Com posterior aumento, que coincidiu com a fase de máximo crescimento da cultura, com Kc igual a 1,06 , e, em seguida com a maturação observou-se uma redução deste valor. Padrão semelhante foi observado para o feijão-caupi no sistema consorciado, porém, com magnitudes superiores (Tabela 2). Os resultados obtidos para o sistema exclusivo são superiores aos reportados por Maschio et al. (2007), que em trabalho realizado para a cultura do feijãocaupi no município de Teresina - PI, encontraram valores iguais a 0,$66 ; 0,82 ; 1,06$ e 0,60 , para as fases vegetativa, floração, enchimento dos grãos e maturidade fisiológica, respectivamente. Da mesma forma, estes valores foram inferiores aos obtidos por Bastos et al. (2008a), os quais conduziram um experimento com o feijão-caupi, em Alvorada do Gurgéia-PI, e encontraram valores de Kc iguais a 0,80; 0,95; 1,25 e 0,85 para as fases vegetativa, floração, enchimento dos grãos e maturidade fisiológica, nesta ordem.

A partir dos valores médios de Kc foram ajustados modelos em função dos graus dias acumulados, sendo os seus coeficientes demonstrados na Tabela 3, podendo ser aplicados de uma maneira simples e prática no manejo de irrigação das culturas (SILVA et al., 2012).

Tabela 3. Coeficientes do modelo Gaussiano $\left(\mathrm{Kc}=\mathrm{a} \cdot \exp \left(-0,5 \cdot((\mathrm{GDA}-\mathrm{b}) / \mathrm{c})^{2}\right)\right)$ ajustados na estimativa do coeficiente de cultura (Kc) em função dos graus dias acumulados (GDA) para as culturas do milho e do feijão-caupi em sistemas de plantio exclusivo e consorciado sob as condições de Semiárido brasileiro, Petrolina-PE, 2008

\begin{tabular}{lccccc}
\hline \multicolumn{1}{c}{ Sistema de plantio } & $\mathrm{a}$ & $\mathrm{B}$ & $\mathrm{C}$ & $\mathrm{R}^{2}{ }_{\text {Adj }}$. \\
\hline Milho exclusivo & & 1,2509 & 1179,4972 & 526,9940 & 0,97 \\
Feijão-caupi exclusivo & 1,0785 & 969,1739 & 403,4496 & 0,94 \\
Milho consorciado & 1,3004 & 1172,3778 & 576,7093 & 0,86 \\
Feijão-caupi consorciado & 1,3123 & 995,0474 & 452,1302 & 0,96 \\
\hline
\end{tabular}

O modelo Gaussiano com três parâmetros foi o que apresentou os melhores coeficientes de determinação $\left(\mathrm{R}_{\text {Adj. }}^{2}>0,86\right)$, podendo ser caracterizado como um modelo semi-empírico, logo que se utiliza (SILVA et al., 2012). Bons ajustes de modelos correlacionando os valores de $\mathrm{Kc}$ em função dos graus dias acumulados têm sido citados para culturas como cafeeiro (LIMA; SILVA, 2008), feijão-caupi (DETAR, 2009) e cana-de-açúcar (SILVA et al., 2012).

\section{CONCLUSÕES}

Houve uma maior necessidade de água para as culturas do milho e do feijão caupi nos sistemas consorciados quando comparados aos sistemas exclusivos;

Os valores de Kc no sistema de plantio consorciado foram iguais a 0,$90 ; 1,43 ; 1,17$ e 0,72 para o milho e 0,$86 ; 1,25 ; 1,31$ e 0,91 para o feijão-caupi, respectivamente e no sistema exclusivo de 0,86 ; 1,$23 ; 0,97$ e 0,52 para o milho e de 0,$68 ; 1,02 ; 1,06$ e 0,63 para o feijão-caupi, nessa mesma ordem;

O modelo Gaussiano com três parâmetros apresentou ótimo ajuste $\left(\mathrm{R}_{\text {Adj. }}^{2}>0,86\right)$ para a estimativa dos valores de coeficiente de cultura do milho e do feijão caupi em função dos graus-dia acumulados 
em ambos os sistemas de plantio.

\section{REFERÊNCIAS}

ALBUQUERQUE, P. E. P. Sistemas de produção: Cultivo do milho - Manejo de Irrigação. Disponível em: http://www.cnpms.embrapa.br/publicacoes/ milho_6_ed/imanejo.htm. acessado em: janeiro de 2010.

ALLEN, R.G. et al. Crop evapotranspiration: guidelines for computing crop water requirements. Rome: FAO, 1998. 279 p. (FAO, Irrigation and Drainage Paper, 56).

ANDRADE, M. J. B. et al. Avaliação de sistemas de consórcio de feijão com milho-pipoca. Ciência e Agrotecnologia, Lavras, v. 25, n. 2, p. 242-250, 2001.

ANDRADE JÚNIOR, A. S. de. et al. Coeficientes de cultivo da mamoneira em sistema monocultivo e consorciado com feijão-caupi. In: Congresso Brasileiro de Mamona Energia e Ricinoquímica, 3., 2008, Salvador, BA. Anais... Salvador, BA: Embrapa, 2008. 1CD-ROM.

BASTOS, E. A. et al. Coeficiente de cultivo do milho nos Tabuleiros Litorâneos do Piauí. In: Congresso Nacional de Milho e Sorgo. Congresso Nacional de Milho e Sorgo, 27., 2008, Londrina-PR. Anais... Londrina-PR: Embrapa Milho e Sorgo/Associação Brasileira de Milho e Sorgo. 1 CD-ROM.

BASTOS, E. A. et al. Evapotranspiração e coeficiente de cultivo do feijão-caupi no Vale do Gurgéia, Piaui. Irriga, Botucatu, v. 13, n. 2, p. 182-190, 2008.

BEZERRA, F. M. L.; OLIVEIRA, C. H. C. Evapotranspiração máxima e coeficientes de cultura para o milho em Fortaleza, CE. Engenharia Agrícola, Jaboticabal, v. 19, n. 1, p. 8-17, 1999.

CARDOSO, M. J. et al. Arranjo populacional no consórcio milho $\mathrm{x}$ feijão macassar (Vigna unguiculata (L.) Walp.) em regime de sequeiro. Revista Ceres, Viçosa, v. 41, n. 233, p. 19-27, 1994.

CARVALHO, D. F. de et al. Demanda hídrica do milho de cultivo de inverno no Estado do Rio de Janeiro. Revista Brasileira de Engenharia Agrícola e Ambiental, Campina Grande, v. 10, n. 1, p. 112 $-118,2006$.

DETAR, W. R. Crop coefficients and water use for cowpea in the San Joaquin Valley of California. Agricultural Water Management, Amsterdan, v. 96, n. 1, p. 53-66, 2009.

EVANGELISTA, A. R. et al. Composição bromato- lógica de silagens de sorgo (Sorghum bicolor (L.) $\mathrm{MOENCH}$ ) aditivadas com forragem de leucena (Leucaena leucocephala (LAM.) DEWIT). Ciência e Agrotecnologia, Lavras, v. 29, n. 2, p. 429-435, 2005.

FANCELLI, A. L.; DOURADO NETO, D. Ecofisiologia e fenologia. In: FANCELLI, A. L.; DOURADO NETO, D. Produção de milho. Guaiba: Agropecuária, 2000. p. 21-54.

FERNANDÉZ, F. et al. Etapas de desarrolo de la planta de frijol común: Centro Internacional de Agricultura Tropical, Cali, 1982. 26 p.

FERREIRA, V. M. et al. Coeficientes de cultivo do milho em sistemas monocultivo e consorciado com feijão-caupi. In: CONGRESSO BRASILEIRO DE AGROMETEOROLOGIA, 15., 2007, Aracajú. Anais... Piracicaba: SBAGRO, 1998. 1 CD-ROM.

FERREIRA, V. M. et al. Consumo relativo de água pelo milho e pelo feijão-caupi, em sistemas de cultivos solteiro e consorciado. Revista Brasileira de Agrometeorologia, Santa Maria, v. 16, n. 1, p. 96106, 2008.

FREIRE FILHO, F. R.; RIBEIRO, V. Q. Feijãocaupi: avanços tecnológicos. Brasília: Embrapa Informação Tecnológica, Teresina, Embrapa MeioNorte, 2005. 519 p.

GAO, Y. Crop coefficient and water-use efficiency of winter wheat/spring maize strip Intercropping. Field Crops Research, Amsterdan, v. 111, n. 1, p. 65-73, 2009.

LIMA, E. P; SILVA, E. L. da. Temperatura base, coeficientes de cultura e graus-dia para cafeeiro arábica em fase de implantação. Revista Brasileira de Engenharia Agrícola e Ambiental, Campina Grande, v. 12, n. 3, p. 266-273, 2008.

LIMA, J. R. de. S. et al. Balanço hídrico no solo cultivado com feijão-caupi. Revista Brasileira de Ciências Agrárias, Recife, v. 1, n. 1, p. 89-95, 2006.

LOZADA, B.; ANGELOCCI, L. R. Determinação da temperatura base e de graus-dia para estimativa da duração do subperíodo da semeadura à floração de um híbrido de milho (Zea mays). Revista Brasileira de Agrometeorologia, Santa Maria, v. 7, n. 1, p. 3136, 1999.

MASCHIO, R. et al. Coeficientes de cultivo do feijão-caupi em sistemas monocultivo e consorciado com o milho. In: CONGRESSO BRASILEIRO DE AGROMETEOROLOGIA, 15., 2007, Aracajú - SE. Anais... Piracicaba - SP: SBAGRO, 2007. 1 CDROM. 
OLIVEIRA, S. R. M. de. Determinação de parâmetros para estimativa do risco climático no consórcio algodão herbáceo e feijão caupi. 2010. $111 \mathrm{f}$. Dissertação (Mestrado em Agronomia) - Universidade Federal do Piauí, Teresina, PI, 2010.

PAYERO, J. O. et al. Effect of irrigation amounts applied with subsurface drip irrigation on corn evapotranspiration, yield, water use efficiency, and dry matter production in a semiarid climate. Agricultural Water Management, Amsterdan, v. 95, n. 8, p. $895-908,2008$.

POSSE, R. P. et al. Evapotranspiração e coeficiente de cultura do mamoeiro. Engenharia Agrícola, Jaboticabal, v. 28 , n. 4, p. 681-690, 2008.

RIBEIRO, M. S. et al. Coeficiente de cultura (Kc) e crescimento vegetativo de acaiá cerrado associados a graus-dia e desenvolvimento. Irriga, Botucatu, v. 14, n. 2, p. 220-232, 2009.

SILVA, T. G. F. da. et al. Requerimento hídrico e coeficiente de cultura da cana-de-açúcar irrigada no semiárido brasileiro. Revista Brasileira Engenharia Agrícola e Ambiental, Campina Grande, v. 16, n. 1, p. 64-71, 2012.

SOUZA, L. S. B. et al. Eficiência do uso da água das culturas do milho e feijão-caupi sob sistemas de plantio exclusivo e consorciado no Semiárido brasileiro. Bragantia, Campinas, v.70, n. 3, p. 715-721, 2011.

SUYKER, A. E.; VERMA, S. B. Evapotranspiration of irrigated and rainfed maize-soybean cropping systems. Agricultural and Forest Meteorology, Amsterdan, v. 149-3, n. 4, p. 443-452, 2009.

TEIXEIRA, A. H. de C. et al. Delimitação da aptidão agroclimática para a videira sob irrigação no Nordeste Brasileiro. Engenharia Agrícola e Ambiental, Campina Grande, v. 16, n. 14, p. 399-407, 2012. 